\title{
Saúde e trabalho na educação: lutas a partir do Fórum Cosate
}

\author{
Health and work in education: struggles from the \\ Forums
}

\author{
Maria Elizabeth Barros de Barros; Cristiane Bremenkamp Cruz; Jomar Zahn \\ Universidade Federal do Espírito Santo
}

\begin{abstract}
RESUMO:
Este artigo traz discussões acerca de uma trajetória de pesquisa-intervenção em Educação a partir de experiências tecidas no processo de constituição de Comissões de saúde por local de trabalho (Cosates) em escolas públicas de um município do sudeste brasileiro. Acompanha a constituição do Fórum Cosate e a participação de diferentes instituições, além da comunidade civil, nas lutas por políticas públicas que priorizem o cuidado à saúde no âmbito da Educação. Situa a prática da Conversa e da Roda como ferramenta teórico-metodológica para uma experiência ético-política-formadora, como força motriz para a produção de saúde. Como conclusão, o artigo apresenta a potencialidade de coletivos de trabalho nos processos formativos como modo de fazer frente à individualização que nos segmentariza no contemporâneo.
\end{abstract}

Palavras-chave: políticas públicas; educação; saúde; cogestão.

\begin{abstract}
:
This article discusses a research-intervention trajectory in Education based on experiences in the process of constitution of Health Commissions by place of work (Cosates) in public schools of a municipality in the south-east of Brazil. It accompanies the constitution of the Cosate Forum and the participation of different institutions, as well as the civil community, in the struggles for public policies that prioritize health care in the scope of Education. It establishes the practice of Conversa and Wheel as a theoretical-methodological tool for an ethical-political-training experience, as a driving force for health production. As a conclusion, the article presents the potential of labor collectives as a way of facing the individualization that segments us in the contemporary.
\end{abstract}

Key-words: public policies; education; health

DOI: 10.12957/mnemosine.2020.52686

\section{Introdução}

Com este artigo, pretendemos apresentar algumas tessituras que compõem nossa entrada em um fórum de educação sustentado desde 2012, com o objetivo de ampliar conversas e debates sobre a relação entre saúde e trabalho no ambiente escolar, mais especificamente num município do sudeste brasileiro. Entendemos que essa experiência 
Fórum se constitui como uma estratégia de formação importante. Ao problematizar os modos de trabalho no campo da educação, vislumbrou-se um processo formativo que implica reposicionamento subjetivo de educadores, não se limitando, portanto, a transmitir conteúdos considerados imprescindíveis para o trabalho. A tese é outra: que a formação de educadores se faz, principalmente, a partir de diálogos polifônicos.

Este fórum conta com a participação de diferentes instituições, entidades e representantes civis, como um Núcleo de Estudos e Pesquisas de uma Universidade Pública; o Centro de Referência em Saúde do Trabalhador do Estado (Cerest); o Ministério Público (MP); o Sindicato dos Trabalhadores em Educação; o Conselho Municipal de Educação (CME); a Fundação Jorge Duprat Figueiredo de Segurança e Medicina do Trabalho (Fundacentro); a Divisão de Medicina e Segurança do Trabalho da Prefeitura; os profissionais de escolas municipais e de outros órgãos vinculados à Secretaria Municipal de Educação. A amplitude de discussões neste fórum tem se pautado pela direção de coletivizar análises, saberes e fazeres que permeiam as questões laborais no contexto educacional.

Os encontros do fórum têm ajudado a propor e vislumbrar a constituição do que chamamos de Comissões de Saúde por local de trabalho (Cosates) nas escolas. As Cosates configuram uma aposta coletiva na produção de espaços cogestivos de avaliação do trabalho, tendo como diretriz subsidiar o compartilhamento, a circulação de afetos e de palavra em torno do tema saúde do trabalhador, que emerge das questões enunciadas pela Secretaria de Educação, a qual constata um aumento do absenteísmo ${ }^{1}$ nas escolas em função do adoecimento de trabalhadores/as das escolas.

É importante ressaltar que não pretendemos tornar as Cosates um modelo a ser implementado, tampouco apostamos que esta seja a única forma de organizar espaços cogestivos de produção de saúde na escola. As Cosates são o dispositivo que experimentamos, apostando que outros podem ser inventados, a depender dos contextos singulares e dos trabalhadores envolvidos em territórios específicos de atuação.

Nosso objetivo é dar visibilidade a um trabalho que não está prescrito, mas que é realizado cotidianamente. Assim, afirmamos uma aposta de nos orientarmos por uma análise micropolítica ${ }^{2}$ de acompanhamento dos processos em curso, o que significa dizer que pretendemos incluir uma abordagem que considera e privilegia relações de força atualizadas nos encontros, produzindo subjetividades e modos de viver mais potentes e menos limitadores. Apostamos, também, na análise dos processos de trabalho e no compartilhamento de estratégias de ação como formas genuínas de fazer frente à 
massificação, sujeição e despotencialização da vida coletiva. $O$ fórum como um dispositivo formativo, portanto.

Além disso, vale frisar que a política do conhecimento com a qual nos conjugamos é pautada na inventividade e na construção de sentidos e práticas inovadores na constituição da tessitura do viver. Deste modo, nos distanciamos de uma política de representação de supostos mundos objetivos e já dados. Orientamo-nos por questões, tais como: é possível uma Política de Atenção à Saúde do Trabalhador em Educação? É importante e, por que não dizer, necessário, falar de saúde no trabalho? Discutir o trabalho na educação?

Diante do alto índice de absenteísmo e das sofreguidões compartilhadas cotidianamente pelos trabalhadores da educação, notamos a pertinência cada vez mais urgente de incluirmos nos espaços de trabalho um tempo propício ao diálogo sobre o tema (de modo transversal ${ }^{3}$ e lateralizado). Desse modo, espera-se que esses espaços se configurem como um lugar de construção coletiva do saber-fazer e, assim, possamos nos fortalecer coletivamente e "reencantar o concreto"4 de nossas práticas, no sentido de gerar condições efetivas de partilha da sensibilidade e alteração das condições coletivas de ação nos espaços onde atuamos. Considerando, como já mencionado, os altos índices de adoecimento e absenteísmo referidos ao trabalho em educação, cabe, ainda, ressaltar que, na ótica das Clínicas do Trabalho, a compreensão desses fenômenos não deve se pautar numa unicidade causal, nem numa perspectiva médica biologizante. É preciso trazer à tona a multidimensionalidade da produção do adoecimento (organização, condições, carga, jornada, política educacional, entre outros). O trabalho não pode ser analisado de maneira isolada, tendo em vista a concorrência de vários fatores no exercício dessa atividade ${ }^{5}$, muitas vezes geradora de fadiga e sofrimento. Assim sendo, acreditamos na importância de estabelecer estratégias coletivas de enfrentamento quanto aos problemas levantados pelos trabalhadores. Esse tem sido o exercício constante nas práticas do Fórum Cosate e seu respectivo projetopiloto.

Vale ainda ressaltar que os espaços de diálogo parecem limitados quando se apresentam disponíveis apenas durante os intervalos das aulas, nos corredores, no pátio, nos momentos antes ou após o expediente e nos encontros do "cafezinho". Consideramos que é cada vez mais pertinente garantir, durante a jornada de trabalho na escola, a inclusão de momentos de discussão e construção compartilhada, que abram caminhos e deem suporte para a ação cotidiana. Os processos de formação se efetivam 
nesse exercício cotidiano de problematização das práticas instituídas na rede educacional e, portanto, não podem ficar reduzidos a cursos que privilegiam modos informativos e conteudistas.

Nesta perspectiva, surge a aposta no projeto de lei das Cosates, que tem sido debatido por uma ampla comunidade de pesquisadores e trabalhadores da educação, com vistas a contribuir para a garantia e sustentação de espaços democráticos de conversas e análises a partir do trabalho, sobre o trabalho e no trabalho.

Conduzimos esta pesquisa-intervenção na ampliação da extensão dialógica como proposta metodológica, ética e política. As Cosates são uma estratégia da Política Nacional de Saúde do Trabalhador para dar passagem à participação, ao protagonismo e à autogestão dos trabalhadores. O Fórum Cosate, como experimentação coletiva na construção de Políticas Públicas, é também uma aposta de que novas paisagens existenciais sejam experimentadas, no exercício de um novo e provisório corpo atento às meticulosidades e aos interstícios que constituem a produção de saúde docente.

Uma gama de ações tem sido realizada, tais como: reuniões com professores nas escolas; visitas a setores de saúde do trabalhador e de perícia laboral; reuniões com diferentes setores da gestão municipal; parcerias interinstitucionais e com o sindicato dos trabalhadores, entre outras, diagramando e visibilizando problemáticas e estratégias de ação coletivizadas.

O próprio método de escrituração desta pesquisa e de sua constituição também são pautados em rodas de conversação. Como aponta Stengers (1990), pesquisar é produzir interesse e controvérsias que constituam questões políticas e enfatizem a reinvenção de sentidos, criação de histórias, vínculos e relações de força favoráveis à sustentação da produção de diferença e engendramento de multiplicidades.

\section{Desenvolvimento}

\section{Pistas de experiências concretas: o aumento da potência de agir no Fórum Cosate}

A experiência formativa narrada neste trabalho pauta-se pela construção de políticas públicas "com", e não "para" os trabalhadores. O projeto-piloto realizado teve como foco experimentar a efetivação de Cosates a partir de uma inauguração (temporária) em duas escolas da rede municipal. Em cada uma das escolas, foram promovidos debates para a eleição dos membros que integraram o projeto-piloto de experimentação das Cosates. Os membros então eleitos participaram de curso de formação, o qual se propôs subsidiar o trabalho nas Comissões. Cabe destacar que o 
formato "curso" foi tomado como um disparador para aquecer um processo formativo ampliado. A ideia de disparador indica que tal ação pode se desdobrar em distintas direções e comportar desequilíbrios e tensões, bem como oportunidades, mudanças e derivações que extrapolam o próprio formato do curso tal como planejado.

Vale ainda dizer que ambas as escolas foram eleitas após debates no Fórum, evento no qual se propôs um curso de formação para os trabalhadores da educação voltado para a discussão do Projeto de Lei que instituiria as Cosates. Os encontros ocorreram de maneira intercalada: o primeiro foi na Fundacentro; na semana seguinte, na EMEF Manoel Carlos de Miranda e, a seguir, no CMEI Olindina Leão Nunes. Depois de feito o primeiro ciclo, retomava-se a mesma escala de intervalos dos espaços coletivos até que foram concluídos onze encontros, num percurso ocorrido sequencialmente.

Nestas experiências de organização do projeto-piloto, pudemos, ainda que temporariamente, provocar uma reorganização da carga horária dos professores - que foi arduamente negociada com a Secretaria Municipal de Educação - para viabilizar a contratação de professores que substituiriam as trabalhadoras que participariam da experiência-piloto. Cada um dos membros das Cosates foi liberado da regência de classe ou de outras tarefas na escola por um período de 4 horas semanais. Tal decisão possibilitou a participação deles em onze encontros, quatro horas por semana, para atividades de trabalho, além do processo de dispersão, que compreendia ações programadas pelas trabalhadoras a serem desenvolvidas nos seus locais de trabalho. Os participantes traziam as experiências laborais e, conjuntamente, debatíamos alguns conceitos e conteúdos nos encontros presenciais. No momento das atividades de dispersão, os membros da comissão discutiam os temas dos encontros - por um lado articulando suas práticas no ambiente de trabalho e, por outro, espraiando o conteúdo estudado para outros trabalhadores da escola.

Para que as Cosates possam se instituir, é necessário um processo de formação com a finalidade de discutir e propor modos de ação nos locais de trabalho, tais como: mapas de risco nas escolas, entrevistas, encontros de análise sobre o trabalho em educação, conversas sobre o que produz saúde e adoecimento nas escolas, dentre outros temas que seriam elencados ao longo do processo formativo. Nos encontros, discutia-se sobre riscos e potencialidades à saúde com relação ao trabalho na escola, em articulação à rede de serviços em saúde do trabalhador. 
Durante estes encontros de formação, um dos principais desafios trazidos pelos membros das comissões foram falas que expressavam uma descrença dos colegas quanto à efetividade das Cosates, como por exemplo: "vocês participam das Cosates para escapulir da sala de aula...”, entre outros sentidos despotencializadores do processo.

Produzir sentidos potentes para as comissões, para as Cosates, que não reduzam tal experiência à ideia de "ajuntamento de pessoas para morcegagem, escapulida do trabalho para tomar cafezinho" etc., foi um grande desafio inicial. A proposta era construir, com os trabalhadores, estratégias para que tais comissões pudessem se constituir como dispositivo importante para colocar em análise os processos de trabalho, vislumbrando sua transformação e, consequentemente, a produção de saúde no trabalho.

Tal proposta não tem sido tarefa fácil, pois a descrença nas políticas governamentais e o avanço de medidas neoliberais têm produzido profundo descrédito e desânimo entre os trabalhadores. Neste sentido, é importante situar o momento de retrocesso pelo qual passamos no que se refere às políticas públicas no município. Como exemplo, podemos mencionar que o termo "pacote de maldades" foi cunhado entre os servidores do município para se referir a projetos de leis que retiram direitos básicos adquiridos em processos históricos de luta. O projeto de lei n.167/2017, de autoria do então prefeito Audifax Barcelos (REDE), por exemplo, foi aprovado e dispõe sobre o auxílio-alimentação. Tal projeto prevê que o servidor afastado por motivo de doenças em pessoas da família, licença, tratamento de saúde, férias, capacitação, exercício de mandato - inclusive em sindicato -, entre outros, deixe de ter direito a auxilio alimentação. Além disso, se a jornada de trabalho do servidor for reduzida, mesmo que seja por determinação de sua chefia imediata, este também sofrerá desconto no benefício.

É importante pontuar que nos momentos de lamento e diagnóstico de situaçõeslimite como estas vivenciadas no chão da escola, acompanhava-se, também frequentemente, um traçar de linhas propositoras, de articulação comunitária em prol da luta pela garantia de direitos. Esta dinâmica marca passagens de posturas centradas na queixa para uma postura organizada em torno de uma análise coletiva, visando a mudanças e a ações concretas. Esse era um dos objetivos das Cosates: funcionar como propositora e articuladora de ações. Não se trata de uma proposta idealizada de desaparecimento das adversidades; ao contrário, o que movimenta as Cosates é, exatamente, sua força de produção de controvérsias nas escolas, como agonísticas que 
colocam em debate uma multiplicidade de modos de pensar, sentir, trabalhar e lutar por dignidade no trabalho. Deste modo, a aposta ético-política do fórum é a de uma postura frente aos conflitos na direção de produzir manejo das controvérsias e não a negação sumária das diferenças. Não se trata tampouco de acirrar disputas que incitem ao ódio, mas de legitimar diferenças tendo como diretriz a coletivização de discussões e a construção de caminhos políticos que beneficiem a comunidade escolar na direção da consolidação de políticas públicas para o setor educacional.

Tal multiplicidade mantém-se ancorada em ambivalências, momentos de engajamento, de aposta no coletivo e também momentos de desânimo. Entretanto, na continuidade do trabalho do Fórum Cosate, vimos um número cada vez maior de elementos levados para a análise coletiva, aliado ao surgimento de estratégias para ação. Quer dizer, diante de muitos vetores adoecedores e da condição produtivista que marca o modo capitalista de produção, os desafios das situações locais e experiências vividas coexistem com um devir de lutas. O desafio cotidiano nesta pesquisa-intervenção foi, portanto, o olhar para o emaranhado de forças e tecer saídas possíveis coletivizadas.

Outro evento no processo de formação das Cosates merece destaque, uma vez que nos indicou linhas de potência no enfrentamento de desafios que o cotidiano nas escolas nos coloca. Em certa ocasião, discutiu-se um texto chamado: "Saúde, cadê você? Cadê você?" (BRITO; ATHAYDE; NEVES, 2003) dentro do contexto de uma atividade de dispersão. No dia proposto para a atividade, no entanto, não fora possível reunirem-se os integrantes, pois a escola estava ocupada por desabrigados em decorrência das fortes chuvas no município. Entretanto, uma reorganização do planejado promoveu maior engajamento dos participantes no encaminhamento das estratégias para driblar as adversidades e oferecer suporte, o que, inesperadamente, aumentou o número de pessoas engajadas na tarefa em curso. Tal movimento nos indicou a força de contágio que as comissões podem produzir. Esse foi um bom indicador. Como criar estratégias que fortaleçam contágio e aquecimento de redes?

\section{O projeto de lei}

A partir de uma série de discussões, foi produzida uma proposta de projeto de lei a ser apresentada aos órgãos competentes, instituindo as Cosates no município, no intuito de forçar a palavra em torno do tema saúde no ambiente escolar ${ }^{6}$. A estratégia de Comissões por Local de Trabalho não é invenção nossa, é um dispositivo previsto nas regulamentações que direcionam as políticas de saúde do trabalhador no Brasil. 
Tais diretrizes, baseadas no Movimento Operário Italiano (MOI), partem do pressuposto de que os trabalhadores não podem ser dispensados da análise dos processos de trabalho. Não cabe apenas aos especialistas a função de analisar as condições de trabalho em situações concretas. O trabalhador é convocado como protagonista nesse processo. Um diálogo entre saberes acadêmicos e saberes da experiência dos trabalhadores é o caminho para a transformação das condições de trabalho que produzem adoecimento.

Como já mencionamos, uma preocupação do Fórum foi a de construir uma lei com a participação dos sujeitos que operam diretamente nesse campo - uma política pública formulada com e não para os trabalhadores -, seguindo as diretrizes do MOI. A implantação das Cosates como política pública configura-se num desafio, pois objetiva reunir os profissionais da educação num horário comum para o desenvolvimento das atividades da Comissão, tendo em vista a possibilidade de fazer frente ao processo de segmentarização e individualização tão frequentemente alimentado nas escolas. Tal entrada implica, pois, desafiar um modo de organização do trabalho em educação que considera a ação nas escolas como reduzida à regência de classe, configurando o que é popularmente chamado de "professor auleiro".

Afinal, a organização do espaço escolar (em salas, turmas, turnos, aulas) imprime um ritmo em que, sozinho, o trabalhador precisa lidar com as adversidades do cotidiano de trabalho (LOUSADA; BARROS, 2008). Momentos de análise coletiva dos processos laborais, fundamentais para a promoção da saúde numa perspectiva ampliada (CLOT, 2010), são raros ou inexistentes. Nessas circunstâncias, o modo de funcionamento construído com o trabalho das Cosates é fruto de um esforço coletivo e de uma ação colaborativa que envolve diversos segmentos, a fim de experimentarmos outros modos de habitar e produzir as escolas.

A parceria entre a Secretaria Municipal de Educação e movimentos populares, como o Fórum Cosate, tal como se deu e ainda hoje se efetiva, indica a viabilidade da construção de uma política efetivamente pública, a qual pode ser definida como efeito de um desejo e ação coletivos (BENEVIDES; PASSOS, 2005). Tal aspecto apresentase, constantemente, no modo de envolvimento dos participantes com o Projeto, no seu engajamento com as atividades e as produções possibilitadas a partir disso. De modo geral, é possível afirmar que as ações das Cosates perspectivaram um trabalho coletivo, colaborativo e cogestivo. As Cosates não se constituem como uma mera execução de 
atividades demandadas por um agente externo, mas se organizam como uma produção dinâmica oriunda do desejo de realizar esse trabalho no concreto das situações.

Esta observação é relevante se considerarmos que várias comissões existentes em diversos órgãos governamentais são tomadas como "mais um trabalho, mais uma obrigação", algo meramente burocrático ou enfadonho. Cabe, nesse sentido, avaliar a longo prazo os efeitos de promoção de saúde e prevenção de adoecimento possíveis de serem disparados por tais Comissões. Desse modo, é possível estimar a sua potência para produção de cuidado em saúde e educação, além, inclusive, de sua potência, tendo em vista reduzir os custos que o alto índice de absenteísmo do trabalhador adoecido acarreta para os cofres públicos.

Vale ressaltar que esta argumentação em torno dos possíveis ganhos econômicos para os cofres públicos constituiu a principal moeda no processo de negociação com a secretaria municipal de educação. Talvez tenha sido este o argumento que tornou possível viabilizar a contratação de trabalhadores substitutos para cobrir os membros das Cosates no momento em que estes estivessem atuantes nas comissões. Vale ressaltar que, nos processos formativos com os trabalhadores, tentávamos operar para além desta dimensão econômica, perspectivando os modos de organização e luta por autonomia do trabalho. Entre os trabalhadores, no entanto, havia, desde o início, uma desconfiança e apreensão quanto ao papel fiscalizador que as Cosates poderiam adquirir.

O modo dialogado e a construção da função-Cosate como disparadora de discussões locais para a análise coletiva do trabalho caracterizou-se pelo esforço constante de deslocamento de um suposto lugar "dado" e "fechado" para as Cosates. Essa nova forma de atuar chamou a atenção para seu processo de construção contínua, substituindo a ideia de fazer para pela de atuar com, propiciando o que se pode designar por vigilância como acompanhamento de processo. Sendo assim, a fiscalização foi compreendida num exercício de validação coletiva e não de regulamentação externa. Nesta perspectiva, os trabalhadores assumem o papel de "atores", de sujeitos capazes de produzir e avaliar as ações tomadas. Essa direção de práticas tem suas bases nas enquetes operárias da primeira metade do século XIX nos países europeus que visavam ao conhecimento das condições de trabalho nas fábricas, de modo a conduzir os trabalhadores a um raciocínio crítico frente a elas. Tais enquetes deram nascimento ao trabalho de Ivar Oddone (1986) e um grupo de trabalhadores que criaram o Modelo Operário Italiano (MOI), movimento sindical italiano, com uma proposta de 
constituição de Comunidades Científicas Ampliadas (CCA). No contexto brasileiro essas comissões foram nomeadas Comunidades Ampliadas de Pesquisa (CAP).

Foi no exercício de analisar coletivamente os processos de trabalho que as conversas sobre saúde e trabalho puderam ganhar outros tons, para além da dimensão de se pautar apenas na tríade trabalho/sofrimento/doença e de configurar uma fiscalização externa. Mais do que labutar para viver, ou seja, para suportar o trabalho, os espaços de conversa sobre os processos e modos de organização das atividades na escola tiveram como efeito criar novos modos de se relacionar nas redes em que esta ampla tessitura se compõe.

Emergiram enunciados tratando do trabalho como algo que pode produzir saúde, aproximando-se de sua definição como "um poder de ação sobre si mesmo e sobre o mundo, adquirida junto dos outros" (CLOT, 2010: 111). Ou seja, trata-se de perspectivar a produção de saúde no trabalho como exercício coletivo de colocar em análise os processos ligados à atividade e, por isso mesmo, intervir, deslocar, criar novo contexto para viver a partir da construção grupal de alternativas aos problemas que surgem a cada vez. A aposta com as Cosates é produzir modificações importantes, fomentando o trabalhador da educação como gestor e agente fundamental no processo de conhecimento e análise das atividades que realiza.

\section{Considerações finais}

Nas conformações dos modos de vida atuais, em que se sobrepõe uma lógica individualizante marcada pela retirada de direitos adquiridos - os quais eram fruto de processos históricos de lutas -, o desafio que se coloca aos movimentos que intencionam a construção de uma política efetivamente pública é o de criar um chão possível para a produção de experiências em que as pessoas possam se reunir para conversar, refletir, compartilhar lamentos e táticas de ação.

Ao que essa perspectiva nos conduz, tendo em vista o processo formativo que empreendemos junto às Cosates? Conduz-nos à aposta permanente na possibilidade da construção de um comum, sem garantias a priori. Afinal, o que produzimos em nossos trabalhos retroage sobre nós, viabilizando modos de subjetividade mais ou menos conectados com regiões de força e o aumento da potência de agir nos coletivos. Assim, o que esteve em jogo neste trabalho foi uma abertura para a coconstrução de outros mundos e, em última instância, para a criação de paisagens existenciais comprometidas com a coprodução do comum. Apostar nas Cosates como estratégia para uma formação 
inventiva foi vislumbrar pequenas rasuras no modo habitual e automático de nos conduzir, abrindo brechas que apontem, no percurso, para a obra inacabada e a feitura movente de nós mesmos. Tal composição só é possível quando nutrimos espaços de diálogos, compartilhando, fazendo, aquecendo redes para construir os cotidianos escolares que desejamos habitar.

\section{Referências}

BENEVIDES, R.; PASSOS, E. A humanização como dimensão pública das políticas de saúde. Ciênc. saúde coletiva [online]. v.10, n.3, p. 561-571, 2005.

BOTECHIA, F.; ATHAYDE, M. Conversas sobre o trabalho sob o ponto de vista da atividade: algumas abordagens metodológicas. In: BARROS, M. E. B.; HECKERT, A. L. C.; MARGOTO, L. (Orgs). Trabalho e saúde do professor: cartografias no percurso. Belo Horizonte: Autêntica, 2008, p. 43-70.

BRITO, J.; ATHAYDE, M.; NEVES, M. Y. (Org.) Caderno de textos: programa de formação em saúde, gênero e trabalho nas escolas. João Pessoa: Universitária/UFPB, 2003.

CLOT, Y. Trabalho e poder de agir. Trad. Guilherme João de Freitas Teixeira e Marlene Machado Zica Vianna. Série: Trabalho e Sociedade. Belo Horizonte: Fabrefactum, 2010.

DELEUZE, G.; GUATTARI, F. Mil platôs: capitalismo e esquizofrenia (Vol. 3). Rio de Janeiro: Ed. 34, 1996.

GUATTARI, F. A transversalidade. In: Revolução molecular: pulsações políticas do desejo. São Paulo: Brasiliense, 1981, p. 88-105.

GEHRING JUNIOR, G. et al. Absenteísmo: doença entre profissionais de enfermagem da rede básica do SUS de Campinas. Revista Brasileira de Epidemiologia, v. 10, n. 3, p. 401-409, 2007.

LOUSADA, A. P.; BARROS, M. E. B. Trabalho docente: entre prescrições e singularidades. In: BARROS, M. E. B.; HECKERT, A. L. C.; MARGOTO, L. (Org.). Trabalho e saúde do professor: cartografias no percurso. Belo Horizonte: Autêntica, 2008, p. 79-100.

ODDONE, I. Ambiente de trabalho: a luta dos trabalhadores pela saúde. São Paulo: Hucitec, 1986.

STENGERS. I. Quem tem medo da ciência? Ciência e poderes. São Paulo: Siciliano, 1990.

VARELA, F. O reencantamento do concreto. Cadernos de Subjetividade: Saúde e Loucura. São Paulo: Editora Hucitec, n. 11, p. 71-86, 2003.

Maria Elizabeth Barros de Barros Universidade Federal do Espírito Santo

E-mail: betebarros@uol.com.br 


\title{
Cristiane Bremenkamp Cruz \\ Universidade Federal do Espírito Santo \\ E-mail:crisbremenk@gmail.com
}

Jomar Zahn

Universidade Federal do Espírito Santo

E-mail:jomarzahn@gmail.com

\begin{abstract}
${ }^{1}$ A origem da palavra absenteísmo é francesa (absenteisme) e significa falta de assiduidade ao trabalho ou outras obrigações sociais, o que ocorre, frequentemente, em função de processos de adoecimento do trabalhador. É também conhecido como ausentismo ou absentismo, cuja definição pode ser caracterizada como o hábito de não comparecer ou de estar ausente ao trabalho; falta de assiduidade, ou seja, ausências ao trabalho quando se deveria estar presente (GEHRING JUNIOR et al., 2007).
\end{abstract}

2 Para Deleuze e Guattari (1996), fazer análise micropolítica não tem nada a ver com tamanho: não se trata de pensar que o grande - a sociedade, o Estado - se distingue do pequeno - o indivíduo e suas relações intra e interpessoais, tais como homem-mulher, patrão-empregado, enfim, o pequeno cotidiano da vida em família, na escola, em casa ou no hospital, a pequena parte ou unidade. Micro refere-se à dimensão dos processos de constituição da realidade: a realidade em vias de se instituir e desmanchar. Já macro diz respeito à realidade em suas formas constituídas - aqui, também, tanto no nível individual quanto grupal. Daí decorre, segundo os autores, que "tudo é político, mas toda política é ao mesmo tempo macropolítica e micropolítica” (DELEUZE; GUATTARI, 1996: 90).

3 Trata-se de um conceito proposto por Guattari, em 1964, que aponta para a quebra da organização comunicacional que hierarquiza verticalmente os diferentes ou horizontaliza os iguais num espírito de corpo. A desestabilização destes dois eixos organizativos é feita pela transversalidade (GUATTARI, 1981). Neste terceiro eixo, não é mais possível ou necessária a fixação de atores e saberes, isto é, as fronteiras interferem umas nas outras, experimentando-se a dimensão fora das organizações, na qual o grupo vivencia sua dimensão de coletivo.

${ }^{4}$ Fazemos referência ao convite de Francisco Varela (2003), ao nos convocar à destestabilização e ao estranhamento diante de modos habituais de se relacionar, pois, segundo o autor, "é no momento durante o qual ocorrem colapsos que efetivamente se realiza o nascimento do concreto" (VARELA, 2003: 76).

5 Entendemos atividade como "a forma como os trabalhadores se engajam, a partir dos meios de que dispõem ou inventando outros, na gestão dos objetivos do trabalho" (BOTECHIA; ATHAYDE, 2008).

${ }^{6}$ Vale destacar que, a partir do trabalho do fórum, um projeto de lei foi elaborado e enviado para a câmara municipal da Serra/ES. Tal projeto foi aprovado e, então, se instituiu a lei 4513/2016, que criou a Comissão de Saúde do Trabalhador da Educação (COSATE) do Serviço Público do município da Serra/ES e o Conselho das Comissões de Saúde do Trabalhador da Educação (CONCOSATE). 